See discussions, stats, and author profiles for this publication at: https://www.researchgate.net/publication/282570066

\title{
Specialist enemies, generalist weapons and the potential spread of exotic pathogens: Malaria parasites in a highly invasive bird
}

Article in International journal for parasitology · October 2015

DOI: $10.1016 /$ j.jpara.2015.08.008

\section{CITATIONS}

14

4 authors:

Nicholas Clark

The University of Queensland

42 PUBLICATIONS 261 CITATIONS

SEE PROFILE

Farah Ishtiaq

Indian Institute of Science

66 PUBLICATIONS 925 CITATIONS

SEE PROFILE
282

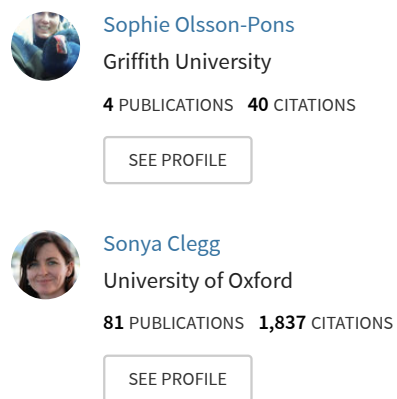

Some of the authors of this publication are also working on these related projects:

Global spread of parasites at the human - domestic animal - wildlife interface View project

Influences of environmental variation on the eco-evolutionary dynamics of an insular bird Zosterops lateralis View project 
Dear Author,

Please, note that changes made to the HTML content will be added to the article before publication, but are not reflected in this PDF.

Note also that this file should not be used for submitting corrections. 


\title{
Specialist enemies, generalist weapons and the potential spread of exotic pathogens: malaria parasites in a highly invasive bird ${ }^{\text {is }}$
}

\author{
Nicholas J. Clark ${ }^{\mathrm{a}, \mathrm{b}, *}$, Sophie Olsson-Pons ${ }^{\mathrm{a}}$, Farah Ishtiaq ${ }^{\mathrm{c}}$, Sonya M. Clegg ${ }^{\mathrm{a}, \mathrm{d}}$ \\ ${ }^{a}$ Environmental Futures Research Institute, School of Environment, Griffith University, Gold Coast Campus, Queensland 4222, Australia \\ ${ }^{\mathrm{b}}$ Natural Environments Program, Queensland Museum, PO Box 3300, South Brisbane, Queensland 4101, Australia \\ ${ }^{\mathrm{C}}$ Centre for Ecological Sciences, Indian Institute of Science, India \\ ${ }^{\mathrm{d}}$ Edward Grey Institute, Department of Zoology, University of Oxford, Oxford OX1 3PS, UK
}

\section{A R T I C L E I N F O}

\section{Article history:}

Received 19 May 2015

Received in revised form 14 August 2015

Accepted 24 August 2015

Available online $\mathrm{xxxx}$

\section{Keywords:}

Acridotheres tristis

Australia

Biological invasions

Enemy release

Haemoproteus

Host-specificity

Plasmodium

Wildlife diseases

\begin{abstract}
A B S T R A C T
Pathogens can influence the success of invaders. The Enemy Release Hypothesis predicts invaders encounter reduced pathogen abundance and diversity, while the Novel Weapons Hypothesis predicts invaders carry novel pathogens that spill over to competitors. We tested these hypotheses using avian malaria (haemosporidian) infections in the invasive myna (Acridotheres tristis), which was introduced to southeastern Australia from India and was secondarily expanded to the eastern Australian coast. Mynas and native Australian birds were screened in the secondary introduction range for haemosporidians (Plasmodium and Haemoproteus spp.) and results were combined with published data from the myna's primary introduction and native ranges. We compared malaria prevalence and diversity across myna populations to test for Enemy Release and used phylogeographic analyses to test for exotic strains acting as Novel Weapons. Introduced mynas carried significantly lower parasite diversity than native mynas and significantly lower Haemoproteus prevalence than native Australian birds. Despite commonly infecting native species that directly co-occur with mynas, Haemoproteus spp. were only recorded in introduced mynas in the primary introduction range and were apparently lost during secondary expansion. In contrast, Plasmodium infections were common in all ranges and prevalence was significantly higher in both introduced and native mynas than in native Australian birds. Introduced mynas carried several exotic Plasmodium lineages that were shared with native mynas, some of which also infected native Australian birds and two of which are highly invasive in other bioregions. Our results suggest that introduced mynas may benefit through escape from Haemoproteus spp. while acting as important reservoirs for Plasmodium spp., some of which are known exotic lineages.
\end{abstract}

(c) 2015 Australian Society for Parasitology Inc. Published by Elsevier Ltd. All rights reserved.

\section{Introduction}

To the detriment of native species, invaders can have competitive advantages in their introduced range that lead to rapid range expansions and the exclusion of native species (DeWalt et al., 2004; Lake and Leishman, 2004). The mechanisms proposed to explain this competitive advantage include release from predators, rapid adaptation to new environments, and changes in hostpathogen interactions (Keane and Crawley, 2002; Lee, 2002). Host-pathogen interactions in particular can influence the way introduced species establish in non-native ranges (Schuler et al.,

New nucleotide sequence data reported in this paper are available in the GenBank $^{\mathrm{TM}}$ database under accession numbers KT777732-KT777740.

* Corresponding author at: Environmental Futures Research Institute, School of Environment, Griffith University, Gold Coast Campus, Queensland 4222, Australia.

E-mail address: nicholas.j.clark1214@gmail.com (N.J. Clark).
2012; Adlard et al., 2015), with two primary hypotheses explaining how pathogens might influence invasion success. The Enemy Release Hypothesis predicts invaders encounter a reduced abundance and diversity of pathogens in the introduced range, allowing the avoidance of costly infections and facilitating ecological release (Keane and Crawley, 2002; Dunn and Hatcher, 2015). The Novel Weapons Hypothesis predicts that invaders carry novel pathogens to the introduced range that can subsequently spill over to immunologically naïve competitors (Callaway and Ridenour, 2004; Adlard et al., 2015).

Haemosporidian malaria parasites (Plasmodium and related Haemoproteus spp.) are vector-borne blood parasites found in birds across the globe (Valkiūnas, 2005; Clark et al., 2014a). Haemosporidian infections in birds can have a range of fitness impacts, from reduced locomotion and fecundity to mortality (Valkiūnas, 2005; Palinauskas et al., 2009; Asghar et al., 2015). Infections are particularly harmful in naïve island hosts, raising important 
concerns for conservation of native avifauna (van Riper III et al., 1986). Recent studies of parasite DNA sequences provide evidence that introduced birds can carry invasive haemosporidian lineages that are detrimental to native birds (Ewen et al., 2012; Hellgren et al., 2014), supporting the Novel Weapons Hypothesis. However, evidence also suggests that introduced birds sometimes encounter a depauperate set of haemosporidian lineages in their introduced range (e.g. house sparrow, Passer domesticus; Marzal et al., 2011), supporting the idea for a competitive edge through infection avoidance. Importantly, the two haemosporidian genera display different specificity strategies, with Plasmodium lineages often infecting a range of species (generalists) while Haemoproteus lineages are more specific (Olsson-Pons et al., 2015). This difference in life history strategies could lead to different capabilities of parasite genera to exhibit Enemy Release or to act as Novel Weapons, particularly in Australia where many birds often carry a high prevalence of Haemoproteus but a low prevalence of Plasmodium spp. (Adlard et al., 2004; Clark et al., 2015). Due to their cosmopoliacterise infections, avian haemosporidian parasites present a of invaders.

The common myna (Acridotheres tristis) is considered by the the world's most invasive avian species (www.issg.org). Introduced mynas are known to spread weeds, damage crops and aggressively defend feeding locations (Pell and Tidemann, 1997). Increases in myna abundance often correlate with declines of native species, possibly due to aggressive competition for roosting and feeding sites (Grarock et al., 2012, 2014) or to the myna's innovative ability to occupy diverse ecological niches (Sol et al., 2011; Griffin and Diquelou, 2015). Following their primary introduction to southmynas from the introduced stock were secondarily introduced along the eastern Australian coast, from where they have spread rapidly (see Supplementary Fig. S1 for map of introduced ranges; Martin, 1996). This sequential pattern of introductions and subsequent expansions may have presented multiple opportunities for mynas to undergo Enemy Release. Due to this expansion and due to their detrimental impacts on native birds, mynas are an ideal study group to investigate mechanisms driving the spread of invaders (Ishtiaq et al., 2006; Grarock et al., 2013).

In its native range in India and SE Asia, the myna carries a high prevalence and diversity of haemosporidian parasites (Ishtiaq et al., 2006, 2007). Importantly, native-range mynas carry some of the most widespread and potentially invasive Plasmodium lineages currently known (Bensch et al., 2009). These include the parasite responsible for the decline of Hawaiian honeycreepers as $P$. relictum lineage SGS1 and Plasmodium elongatum lineage GRW06, both of which are spread by introduced birds in New Zealand (Baillie et al., 2012; Ewen et al., 2012; Ha et al., 2013; Schoener et al., 2013). The potential for mynas to carry introduced haemosporidian parasites was highlighted by Ishtiaq et al. (2006), whose screening of 26 mynas collected from the primary introduction range in the early 1980s confirmed the first detection of lineage GRW04 in Australia. Nevertheless, efforts to identify introduced pathogens require robust phylogeographic analyses that can be hampered by a lack of adequate sampling in the introduced and/ or native range (Ishtiaq et al., 2006; Hu et al., 2011), and we currently do not have detailed knowledge of the haemosporidian lineages infecting Australian native birds (Clark et al., 2014a, 2015). primary and secondary introduction ranges offers a unique opportunity to understand the processes involved during invasive species' range expansions. tan distribution and the existence of molecular techniques to chartractable system to study the influences of pathogens in the spread International Union for Conservation of Nature (IUCN) as one of eastern (SE) Australia from India between 1862 and 1872, common (Plasmodium relictum lineage GRW04; Beadell et al., 2006), as well Moreover, studying the assembly of parasite communities in
Here, we screen introduced mynas and co-occurring native birds in the myna's secondary introduction range in Australia for avian haemosporidian infection. Our results are then combined with published data from the myna's primary introduction range (Ishtiaq et al., 2006) to assess the relative roles of the Enemy Release and Novel Weapons Hypotheses in contributing to the myna's invasion success. We characterised infections using parasite cytochrome- $b$ (cyt- $b$ ) sequences, and we were able to discriminate between native and potentially introduced parasites by using published parasite cyt- $b$ lineages from Australia and the introduced myna's native range to construct regional phylogenies. These data are used to test the following predictions. Enemy Release predicts: (i) lower parasite prevalence and diversity for introduced mynas compared with native mynas, and (ii) lower parasite prevalence in introduced mynas compared with native birds in Australia. Novel Weapons predicts: (i) introduced mynas act as a reservoir for introduced parasite lineages, some of which may be shared with native-range mynas, and (ii) some of these potentially introduced lineages will spill over to Australian native species.

\section{Materials and methods}

We captured native birds using mistnets at field sites in northern New South Wales (NSW) and southern Queensland (QLD), Australia between April 2012 and December 2013. Field sites covered a broad range of habitats including open Eucalypt forest and residential gardens, many of which overlapped with territories used by mynas. A blood sample was taken from the wing vein of each bird and stored in lysis buffer (1\% SDS, $20 \mathrm{mM} \mathrm{NaCl}, 10 \mathrm{mM}$ TRIS pH 8.0 and $10 \mathrm{mM}$ EDTA pH 8.0). Individuals were banded with an Australian Bird and Bat Banding Scheme (ABBBS) metal band and released at the site of capture. A common myna culling program operates in NSW and QLD, and all mynas used for this study were caught as part of this program. Mynas were caught in the secondary introduction range in northern NSW and southern QLD using baited walk-in traps (see Supplementary Fig. S1 for sampling locations). Individuals were then transported to veterinary clinics where blood samples were collected prior to euthanisation by veterinarians.

\subsection{Molecular methods and inclusion of published data}

DNA was extracted from samples using ammonium acetate/ ethanol precipitation (Richardson et al., 2001). We molecularly sexed each sample following the method of Griffiths et al. (1998) to confirm extraction quality and prevent false negatives. Samples were screened for avian haemosporidian DNA (Plasmodium and Haemoproteus) using nested PCR to amplify 479 bp of the parasite cyt- $b$ gene (Waldenström et al., 2004; see Supplementary Table S1 for PCR conditions). Individual flip-cap PCR tubes were used to prevent contamination, and at least three positive and three negative controls were included in each PCR run. All samples were screened twice to reduce false negatives. Positive amplifications were sequenced at Macrogen (Seoul, South Korea). Parasite sequences were aligned in GENEIOUS 5.4 (Biomatters, Auckland, New Zealand the MalAvi database (Bensch et al., 2009). In addition to our sample of native forest birds, we aimed to improve phylogeographic resolution by including Plasmodium sequences that were amplified from migratory wader species that stopover in SE Asia before wintering in SE QLD (Limosa lapponica and Calidris ruficollis; Clark et al., unpublished data).

We combined our results with published data from Australia and India/SE Asia for comparisons of parasite prevalence, diversity and) and identified by comparison with sequences on GenBank 
and phylogeographic structure across the invasive myna's native and introduced ranges. We collected published data by searching the MalAvi database for all studies that molecularly screened birds for avian haemosporidians in Australia and India/SE Asia. From the references identified on the MalAvi database, we recorded total avian malaria prevalence and downloaded the associated parasite sequences (these included sequences from Australia, India, Myanmar, Malaysia, Thailand and the Philippines; (http://mbio-serv2. mbioekol.lu.se/Malavi/index.html), accessed 12 March, 2015). Prevalence and lineage records for native mynas were taken from Ishtiaq et al. (2006, 2007), while data from the invasive myna's primary introduced range in Australia was collated from Ishtiaq et al. (2006). All parasite sequences in the final dataset were compared with the MalAvi database to remove duplicates and gather information on geographic distributions. The dataset included 157 published haemosporidian cyt- $b$ lineages.

\subsection{Parasite prevalence}

Statistical analyses were carried out in R version 3.1.2 (R Development Core Team, 2008; R: A language and environment for statistical computing). To determine if mynas have experienced release from malaria parasites in Australia compared with their native range, we compared parasite prevalence among host groups using generalised linear mixed models (GLMMs), with a binomial error structure. We tested whether prevalence of Plasmodium or Haemoproteus spp. differed between invasive and native mynas as well as between mynas and co-occurring native species by nominating four distinct host groups ('native mynas', 'invasive mynas', 'native Australian spp.', 'native India/SE Asian spp.'). To account for potential differences in screening methods across studies, study identification ('study id') was included as a random term in the model. To explore pairwise comparisons between host groups, we carried out post hoc pairwise interaction contrasts using the R package 'phia' (De Rosario-Martinez, 2013; phia: Post-hoc interaction analysis). Significance of pairwise comparisons was determined following Bonferroni correction, although results were similar when using the less conservative false discovery control method for multiple comparisons (Benjamin and Hochberg, 1995). Separate models were run for Plasmodium and Haemoproteus spp. Due to differences in sample size, we were unable to test for prevalence differences between primary and secondary introduction ranges for introduced mynas.

\subsection{Parasite diversity in native and introduced mynas}

To determine whether introduced mynas carry lower diversity of haemosporidian parasites compared with native mynas, we estimated parasite lineage diversity using the Chao2 estimator, which weights rarely encountered lineages to incorporate un-sampled diversity (Chao, 1987; Dove and Cribb, 2006). This method is particularly useful for comparing diversity estimates between populations with different sample sizes. We generated separate Chao2 diversity estimates and 95\% confidence intervals (CIs) for native and introduced myna populations using 10,000 randomisations in the R package 'fossil' (Vavrek, 2011). Parasite diversity estimates were considered to be significantly different if $95 \%$ CIs did not overlap.

\subsection{Parasite phylogenetics}

We constructed a molecular phylogeny to estimate relationships among parasite cyt- $b$ lineages. Akaike's information criterion was used in jModelTest (v 0.1.1; Posada and Crandall, 1998) to establish the appropriate evolutionary model (GTR + I + G). Phylogenetic reconstruction was implemented in BEAST v1.8.1
(Drummond and Rambaut, 2007) using a Yule prior for branching rates. Four separate runs of 10 million generations were carried out, sampling at every 1000 generations for each run. TRACER (Rambaut and Drummond, 2007; TRACER version 1.4, University of Edinburgh, UK) was used to assess convergence and to test whether the estimated sample size (ESS) for each parameter was sufficient for robust parameter estimates (ESS $>200$ ). We discarded one million generations of burn-in per run, leaving a posterior distribution of 36,000 trees. Three mammalian Plasmodium parasite $c y t-b$ sequences were included as outgroups (Plasmodium malariae, accession AF069624; Plasmodium falciparum, accession AJ298778; Plasmodium reichenowi, accession GU045314).

\section{Results}

\subsection{Parasite prevalence}

In Australia, a total of 260 introduced mynas were screened for haemosporidian infection (234 from this study (sampled in the secondary range in southern QLD and northern NSW) and 26 from the primary introduction range, screened by Ishtiaq et al., 2006; see Supplementary Table S2 for myna sampling locations). In total, 57 introduced mynas were infected with Plasmodium spp. (12 in the primary range ( $46.2 \%$ prevalence) and 45 in secondary range (19.2\%)) and five were infected with Haemoproteus spp. (five in the primary range $(19.2 \%)$ and zero in the secondary range; Fig. 1). The final database included 2038 Australian native birds (and 1017 from Balasubramaniam et al., 2013; 399 from this study; 219 from Beadell et al., 2004; 403 from Zamora-Vilchis et al., 2012), with 78 carrying Plasmodium spp. (4.0\% total prevalence)

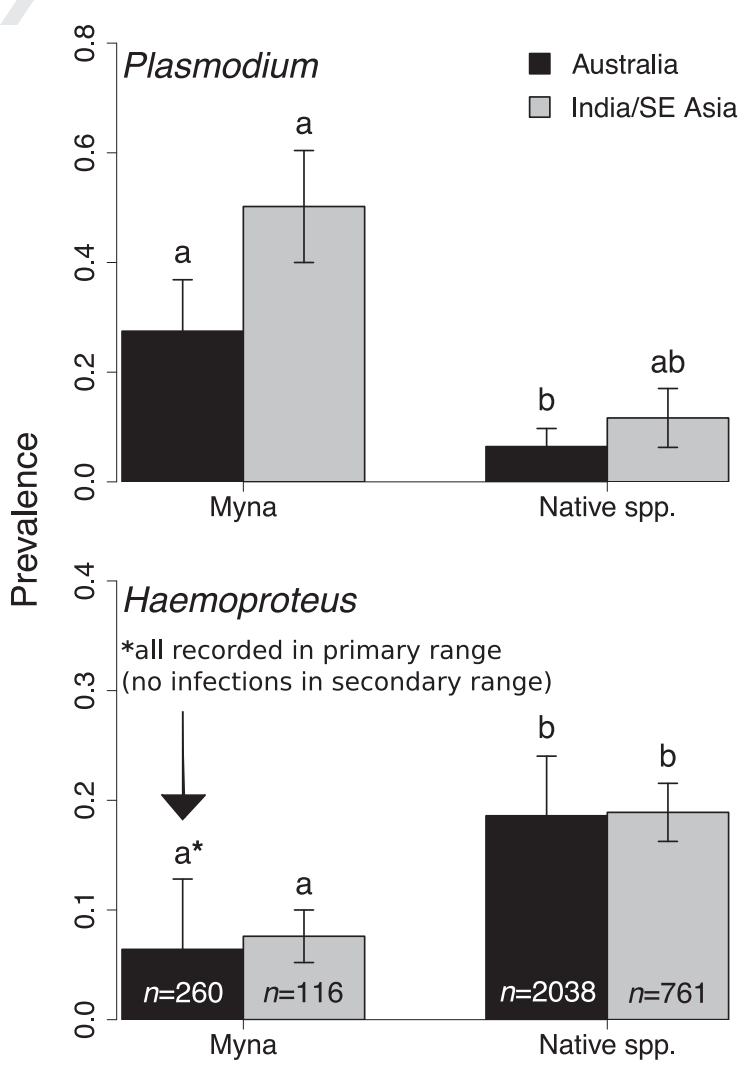

Fig. 1. Prevalence ( \pm S.E.) of Plasmodium spp. and Haemoproteus spp. in mynas and co-occurring native bird communities in the myna's introduced range (Australia; black bars) and the myna's native range (India and southeastern (SE) Asia; grey bars). Letters above bars represent significant groups identified from Post-Hoc comparisons. Note the different y-axis scales. 
and 266 carrying Haemoproteus spp. (13.1\% total prevalence; Fig. 1; Supplementary Tables S2 and S3). Samples from Australian native birds were all collected in sites that overlap with the introduced myna's distribution (Supplementary Fig. S1). Sample sizes and malaria prevalence for the 399 Australian native birds newly tested for this study are presented in Supplementary Table S4.

Ishtiaq et al. (2006, 2007) sampled 116 native-range mynas in India/SE Asia, with 66 infected with Plasmodium spp. (56.9\% total prevalence) and seven infected with Haemoproteus spp. (6.0\% total prevalence; Fig. 1). From the literature search, we extracted infection information from 761 native birds from India/SE Asia (498 from Ishtiaq et al., 2007; and 79 from Ivanova et al., 2015; 184 from Scordato and Kardish, 2014), with 129 carrying Plasmodium spp. infections (17.0\% total prevalence) and 127 carrying Haemoproteus spp. (16.9\% total prevalence; Fig. 1).

Prevalence for Plasmodium spp. varied significantly across host groups after controlling for study id (GLMM: degrees of freedom (df) $=3, z=3.42, P<0.001$ ). Post-hoc pairwise interaction contrasts revealed no significant variation in Plasmodium prevalence between introduced and native mynas (Fig. 1; Supplementary Table S5). Prevalence also did not differ between native mynas and other India/SE Asian native spp. or between Australian native spp. and India/SE Asian native spp. (Fig. 1; Supplementary Table S5). In contrast, Plasmodium prevalence was significantly higher in introduced mynas compared with Australian native spp. (Fig. 1; Supplementary Table S5).

For Haemoproteus spp., prevalence also varied significantly across host groups after controlling for study id (GLMM: $\mathrm{df}=3$, $z=3.70, P<0.001$ ). Haemoproteus prevalence in introduced mynas was significantly lower than in Australian native spp. (Fig. 1; Supplementary Table S5). Haemoproteus prevalence was also significantly lower in native mynas than in native Indian/SE Asian spp. (Fig. 1; Supplementary Table S5). Haemoproteus prevalence did not differ between Australian native spp. and Indian/SE Asian native spp. or between introduced and native mynas. However, all five Haemoproteus infections recorded in introduced mynas were found in the primary introduction range (SE Australia; Ishtiaq et al., 2006; Fig. 1).

\subsection{Parasite diversity and phylogenetic relationships}

The parasite phylogeny included 166 malaria cyt- $b$ lineages recorded to date in Australia and India/SE Asia, including nine previously undescribed lineages (Figs. 2 and 3; see Supplementary Table S6 for GenBank accession numbers of all lineages recorded). We recorded 67 Plasmodium lineages, including 13 lineages that were found in Australia but not found in India/SE Asia and nine lineages that were shared between Australia and India/SE Asia (Fig. 2; Table 1). Of the eight Plasmodium lineages that were phylogenetically associated with Australia, four were recorded in introduced mynas, two of which were also found in Australian native spp. (lineages BELL01 and SCEDEN01; Fig. 2; Table 1). All nine Plasmodium lineages shared between Australia and India/SE Asia were carried by introduced mynas, and eight of these nine lineages were also recorded in native mynas. In addition, five of the Plasmodium lineages that were shared between introduced and native mynas were also recorded in Australian native birds (Table 1), and four of these five lineages were situated in phylogenetic clades that were predominately associated with the myna's native range (lineages ORW1, GRW06, ZEMAC1, and GRW15; Fig. 2). A total of 10 Plasmodium lineages were found to infect introduced mynas, two of which were newly described lineages (MYNA01 and MYNA02; Fig. 2). This compares with 19 Plasmodium lineages that were recorded in native mynas (Ishtiaq et al., 2006, 2007; Fig. 2).
A total of 99 Haemoproteus cyt- $b$ lineages have been recovered from birds in Australia and India/SE Asia (Beadell et al., 2004; Ishtiaq et al., 2006, 2007; Zamora-Vilchis et al., 2012; Balasubramaniam et al., 2013; Scordato and Kardish, 2014; Clark et al., 2015; Ivanova et al., 2015), 55 of which were found in Australia but not found in India/SE Asia (Fig. 3). We found two Haemoproteus lineages infecting introduced mynas (both found in primary introduction sites; Ishtiaq et al., 2006), compared with five Haemoproteus lineages recorded in native mynas (Ishtiaq et al., 2006, 2007). One of the Haemoproteus lineages detected in introduced mynas was also detected in Australian birds and in native mynas (lineage COLL2; Fig. 3). The second lineage detected in introduced mynas (lineage AUS2) clustered strongly with two lineages from native mynas (lineages IND 16 and IND 15; Fig. 3). Parasite lineage diversity estimates were significantly higher for native mynas compared with introduced mynas (Chao2 $(95 \% \mathrm{CI}$ ) = 97.79 (12.45) and 17.25 (3.65), respectively; Fig. 4).

\subsection{Identifying candidate introduced parasite lineages}

Ten of the 15 parasite lineages found in introduced mynas were also found in native mynas, seven of which were situated in nonAustralian clades and represent potentially introduced lineages in Australia (Figs. 2 and 3). For two of these lineages, their infections in introduced mynas represent their only records outside the myna's native range (Plasmodium lineages GLACUC02 and IND 1; Fig. 2; Table 2). In addition, we found two of the three known invasive Plasmodium lineages infecting both native and introduced mynas $(P$. elongatum lineage GRW06 and $P$. relictum lineage GRW04; Ewen et al., 2012; Fig. 2; Table 2). Lineage GRW06 was recorded once in an introduced myna and once in an Australian native bird. In contrast, lineage GRW04 was recorded in five introduced mynas across two sampling sites in Australia, but has not been detected in Australian native species. Similarly, a lineage that was closely related to GRW04 (lineage STNT01; Fig. 2) was absent from resident Australian birds but was found infecting a migratory species that utilises SE Asia during migrations (C. ruficollis). The third recognised invasive Plasmodium lineage, SGS1 (Marzal et al., 2014), was recorded in native mynas but was not found in introduced mynas or in native Australian species (Fig. 2). Aside from lineage GRW06, all other lineages that were shared between myna populations and native Australian birds have relatively wide distributions with as-yet unknown origins (lineages ORW1, FANTAIL01, ZEMAC1, GRW15, COLL2; Table 2). Only one well-sampled native Australian species carried a higher Plasmodium prevalence than mynas (Meliphaga lewinii; Supplementary Table S4); however, this species only carried lineages that likely originated in Australia (lineages BELL01 and MELLEW02; Supplementary Table S4).

\section{Discussion}

Our survey of avian haemosporidian parasites in native and introduced myna populations found mixed support for the Enemy Release Hypothesis. Our results suggest that introduced mynas in Australia encounter lower parasite diversity compared with native-range mynas, and we found a reduction in Haemoproteus prevalence between primary and secondary introduction sites in Australia. However, we found no difference in Plasmodium prevalence between introduced and native mynas. In contrast, Plasmodium patterns support the Novel Weapons Hypothesis, with evidence suggesting that introduced mynas carry a high diversity of potentially introduced Plasmodium lineages in Australia. Indeed, myna populations carried higher prevalences of Plasmodium parasites compared with co-occurring native species in both Australia 


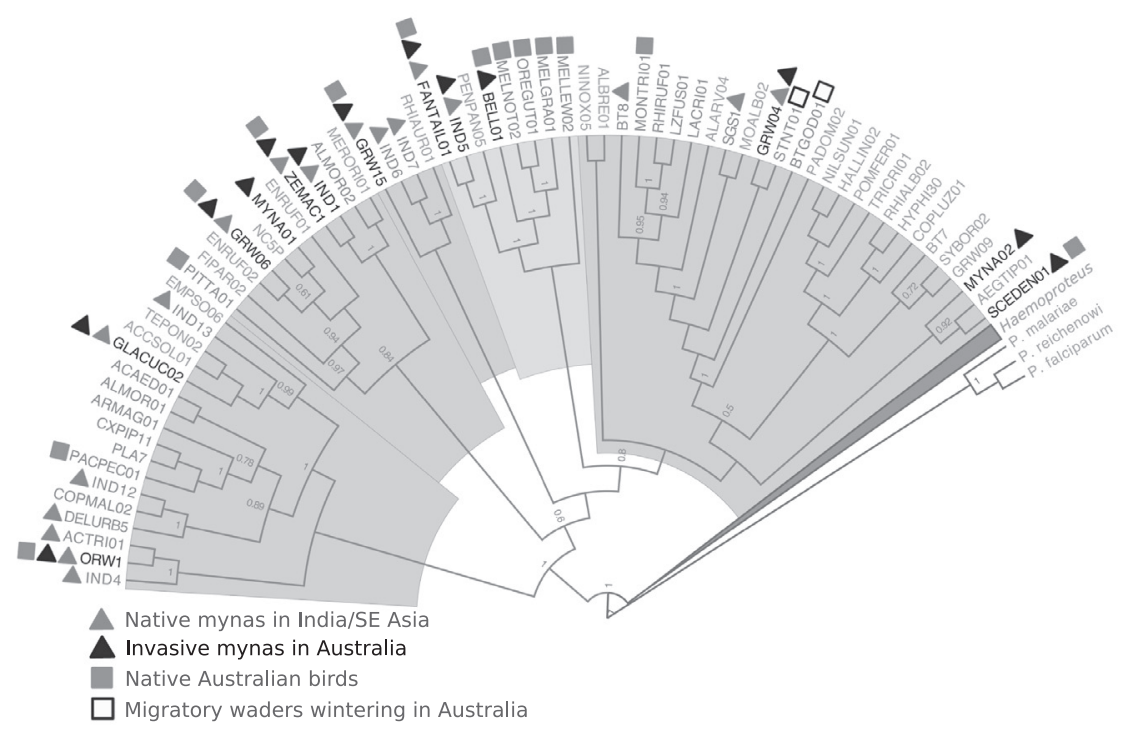

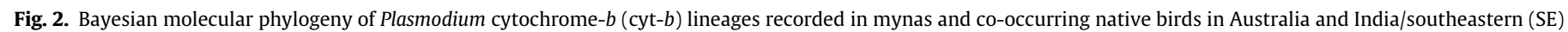

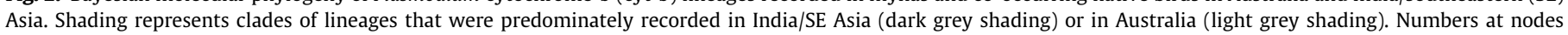
represent Bayesian posterior probabilities of branch placement.

Table 1

Associations between haemosporidian (Plasmodium and Haemoproteus) lineages and avian hosts in Australia and the myna's native range (India/southeastern (SE) Asia).

\begin{tabular}{lcc} 
& Plasmodium & Haemoproteus \\
\hline Lineages found in Australia but not in India/SE Asia & & \\
Total number (\#) of lineages & 13 & 55 \\
\# occurring in introduced mynas & 4 & 0 \\
\# occurring in both introduced mynas and & 2 & \\
Australian birds & & \\
Lineages shared between Australia and India/SE Asia & 9 & 1 \\
Total number of lineages & 9 & 1 \\
\# occurring in introduced mynas & 8 & 1 \\
\# occurring in both introduced mynas and & & 1 \\
native mynas & 5 & \\
\# occurring in introduced mynas, native & & \\
mynas and Australian birds &
\end{tabular}

and India, further suggesting that introduced mynas could act as repositories for maintenance of exotic malaria parasites.

Two of our findings are consistent with expectations of Enemy Release. First, introduced mynas carry a lower diversity of haemosporidian parasites compared with native mynas, a pattern that was strongly significant despite the higher sample size of introduced compared with native mynas. Second, all Haemoproteus infections in introduced mynas were recorded in the primary introduction range in the early 1980s (Baker and Moeed, 1987; Ishtiaq et al., 2006). In contrast, we found no Haemoproteus infections in mynas sampled in the secondary range, despite the much larger sample size for mynas in this region. Moreover, our study strongly supports previous evidence that Haemoproteus infections are common in native species that directly co-occur with mynas in urban and peri-urban environments (i.e. Corvus orru, Threskiornis molucca, Manorina melanocephala, Grallina cyanoleuca and Columba livia; Adlard et al., 2004). This suggests that Haemoproteus spp. have been lost in mynas, possibly due to founder effects as subpopulations were relocated to eastern Australia (Martin, 1996). The release from pathogens may drive the evolution of increased competitive ability for invaders by facilitating a decrease in resource allocation to immune defence and a subsequent increase in allocation to fecundity (Callaway and Ridenour, 2004). Mynas have repeatedly been shown to rapidly increase population sizes in introduced ranges (Holzapfel et al., 2006; Peacock et al., 2007). Given the reduced diversity of parasites infecting introduced mynas in Australia compared with their native range, and the lack of Haemoproteus infections in secondary (and recently sampled) populations, Enemy Release could be one explanation for the introduced myna's incredible success in out-competing native birds.

Differentiating between specialist and generalist pathogens is useful for identifying evidence of Enemy Release, as specialist pathogens are less likely to jump to invaders (Heger and Jeschke, 2014). In contrast to mynas, which carry a relatively high prevalence of Plasmodium infections, Australian native species (including species that directly co-occur with introduced mynas) often harbour a high diversity and prevalence of Haemoproteus lineages (Adlard et al., 2004; Clark et al., 2014a, 2015). This pattern suggests mynas are not utilising habitats that are free of the vectors that transmit Haemoproteus spp. Instead, the paucity of Haemoproteus infections in introduced mynas could reflect differences in host specificity between the two parasite genera, as Haemoproteus lineages are typically more host-specific than Plasmodium (Beadell et al., 2009; Hellgren et al., 2009; Olsson-Pons et al., 2015). Host specificity could also explain how Haemoproteus lineages were seemingly left behind during the myna's secondary introduction. For instance, in a study investigating temporal variation in avian malaria prevalence in an island bird population, the authors found that a host specialist Haemoproteus lineage was frequently carried to the island by vagrant birds without successful establishment (Clark and Clegg, 2015). Considering the high prevalence of Haemoproteus lineages in many Australian species, the lack of Haemoproteus spp. in invasive mynas could signify a competitive advantage through Enemy Release.

An important point to note is the possibility that mixed infections between Plasmodium and Haemoproteus lineages could be occurring in some of our myna samples, as nested PCR tends to underestimate mixed species infections (Valkiūnas et al., 2006). It seems unlikely that our procedure of screening each sample twice would miss active Haemoproteus infections in mynas, particularly since our PCR protocol clearly works well to amplify Australian Haemoproteus lineages. However, it is also possible that Haemoproteus infections do occur in mynas but fail to reach the blood parasitaemia stage (so-called abortive infections; Valkiūnas 


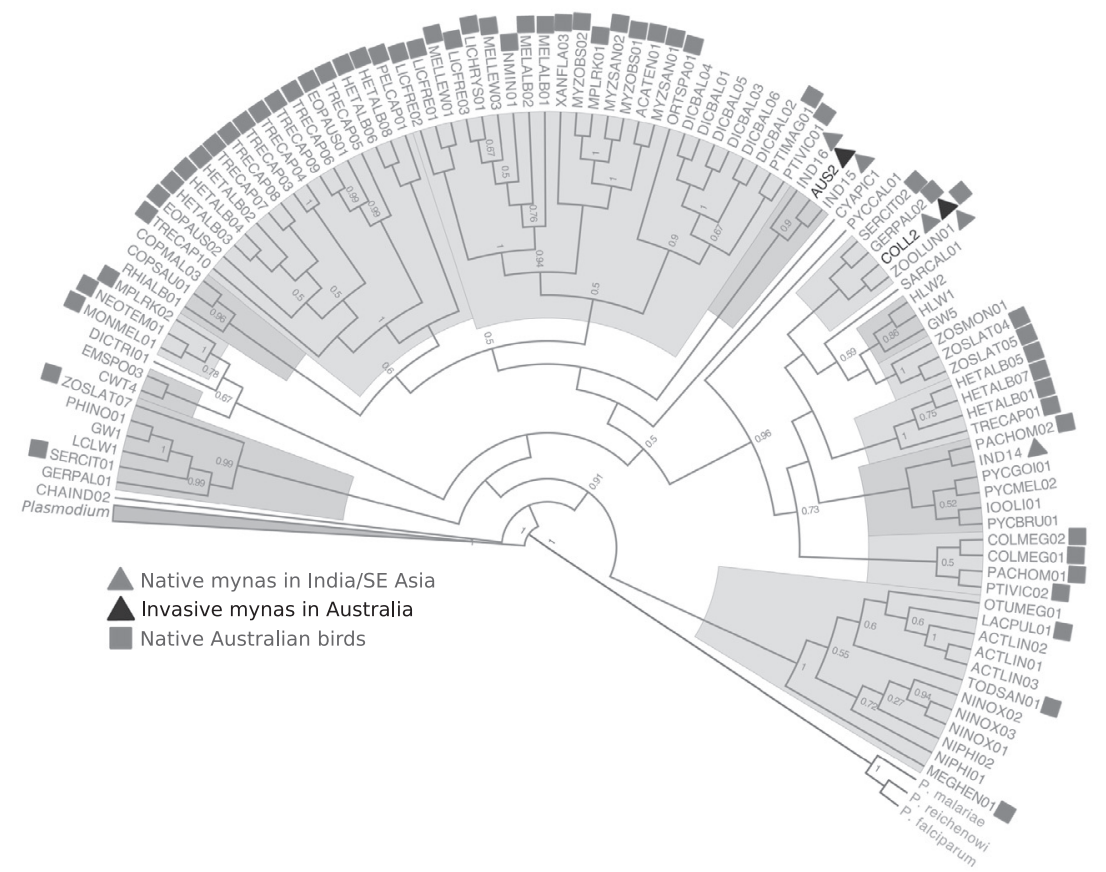

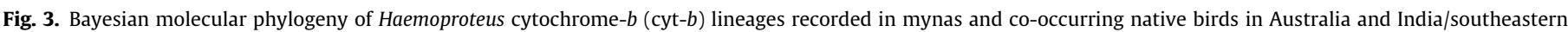

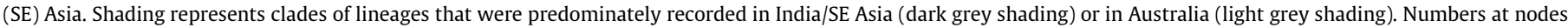
represent Bayesian posterior probabilities of branch placement.

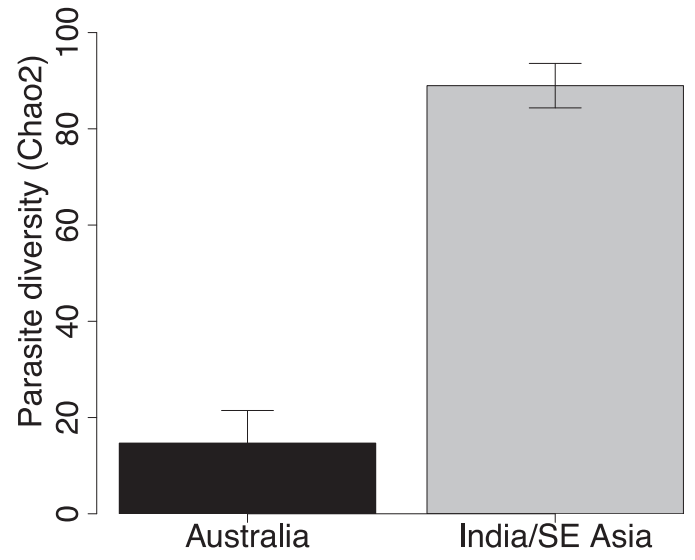

Fig. 4. Chao 2 diversity estimates ( $\pm 95 \%$ Confidence Interval) of haemosporidian lineage diversity infecting introduced mynas (Australia) and native mynas (India/ southeastern (SE) Asia). Estimates were generated with 10,000 randomisations.

et al., 2009). Because many of the myna's competitors are carrying active Haemoproteus infections, it is highly likely that mynas are encountering Haemoproteus parasites in Australia and either do not become infected or are killed off before blood parasitaemia occurs. We suggest that a focused effort incorporating smears and genus-specific primers is warranted before concluding that mynas in the secondary introduction range are free from Haemoproteus infections.

Our findings support the prediction that introduced mynas in Australia carry potentially introduced haemosporidian parasites. For instance, $P$. relictum (GRW04) is considered one of the world's most invasive species (Lowe et al., 2000) due to its devastating impacts in Hawaii (van Riper III et al., 1986; Atkinson and LaPointe, 2009), while P. elongatum (GRW06) has been detrimentally introduced to native birds in New Zealand (Ewen et al.,
2012). Importantly, both GRW04 and GRW06 are capable of infecting a wide range of host species (Hellgren et al., 2009; Howe et al., 2012), although pathogenicity may vary across species (Palinauskas et al., 2009). This tendency towards host generalism indicates that particular avian Plasmodium lineages are at risk of becoming emerging infectious diseases following introductions (Marzal et al., 2014). We found evidence for GRW06 (P. elongatum) infecting native Australian species, suggesting that $P$. elongatum may be a high risk for spillover in Australia. In contrast, we did not find any evidence of GRW04 (P. relictum) infecting native Australian species, despite multiple recoveries in introduced mynas across different sites in Australia. This suggests that GRW04 is transmitted in Australia, but its distribution may be limited by a poor ability to infect native species (Medeiros et al., 2013) or perhaps by a limited vector distribution (Santiago-Alarcon et al., 2012). However, a more worrying explanation is that native birds do not survive when infected with GRW04 and thus we failed to identify infections. This raises an important issue concerning our lack of knowledge about the pathogenicity and transmissibility of particular haemosporidian parasites. For instance, mynas may actually absorb Plasmodium parasites if infections do not progress through their life cycle (Valkiūnas et al., 2014), contributing to a dilution effect (Adlard et al., 2015). Molecular methods can identify infections that previously have been missed or overlooked (Loiseau et al., 2012; Clark et al., 2014b), but they do not identify the viability of hosts for parasite transmission. Understanding transmission is crucial for identifying novel pathogens that exacerbate the impacts of invasive species (Tompkins et al., 2003; Dunn and Hatcher, 2015), and from a conservation standpoint these knowledge gaps are important and should be addressed in future studies.

The high diversity of Plasmodium parasites carried by mynas suggests that mynas are important reservoir hosts across their range, particularly for $P$. relictum. In addition to its high prevalence in native mynas, lineage GRW04 is carried by introduced mynas in the Cook Islands, French Polynesia and Hawaii (Beadell et al., 2006; Ishtiaq et al., 2006). In fact, along with house sparrows 
Table 2

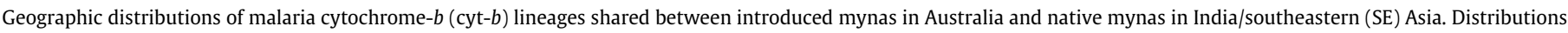
were accessed on the MalAvi public database and all references are contained therein.

\begin{tabular}{|c|c|c|c|c|c|c|c|c|c|c|c|}
\hline \multirow[t]{2}{*}{ Lineage } & \multirow[t]{2}{*}{ Genus } & \multicolumn{10}{|c|}{ Bioregion } \\
\hline & & Asia & Russia & Oceania & New Zealand & E. Europe & W. Europe & N. America & S. America & Africa & Australian native spp. \\
\hline ORW1 & Plasmodium & $\mathrm{X}$ & $\mathrm{X}$ & $\mathrm{X}$ & - & - & $\mathrm{X}$ & - & - & - & $\mathrm{X}$ \\
\hline GLACUC02 & Plasmodium & $\mathrm{X}$ & - & - & - & - & - & - & - & - & - \\
\hline GRW06 & Plasmodium & $\mathrm{X}$ & $\mathrm{X}$ & $\mathrm{X}$ & $\mathrm{X}$ & $\mathrm{X}$ & $\mathrm{X}$ & $\mathrm{X}$ & $\mathrm{X}$ & $\mathrm{X}$ & $\mathrm{X}$ \\
\hline ZEMAC1 & Plasmodium & $\mathrm{X}$ & - & - & - & - & - & $\mathrm{X}$ & $\mathrm{X}$ & $\mathrm{X}$ & $\mathrm{X}$ \\
\hline IND1 & Plasmodium & $\mathrm{X}$ & - & - & - & - & - & - & - & - & - \\
\hline GRW15 & Plasmodium & $\mathrm{X}$ & - & - & - & - & $\mathrm{X}$ & - & - & - & $\mathrm{X}$ \\
\hline FANTAIL01 & Plasmodium & $\mathrm{X}$ & - & $\mathrm{X}$ & - & $\mathrm{X}$ & - & - & - & - & $\mathrm{X}$ \\
\hline IND5 & Plasmodium & $\mathrm{X}$ & - & - & - & - & - & - & - & - & - \\
\hline $\mathrm{GRW} 4^{\mathrm{a}}$ & Plasmodium & $\mathrm{X}$ & $\mathrm{X}$ & $\mathrm{X}$ & $\mathrm{X}$ & $\mathrm{X}$ & $\mathrm{X}$ & $\mathrm{X}$ & $\mathrm{X}$ & $\mathrm{X}$ & - \\
\hline COLL2 & Haemoproteus & $\mathrm{X}$ & - & - & - & $\mathrm{X}$ & $\mathrm{X}$ & $\mathrm{X}$ & - & $\mathrm{X}$ & $\mathrm{X}$ \\
\hline
\end{tabular}

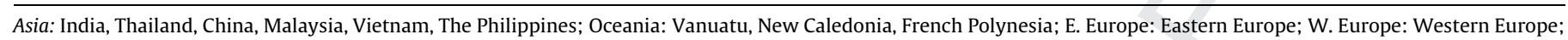
N. America: North America; S. America: South America.

$\mathrm{X}$, lineage present in a particular bioregion; -, lineage has not been recorded in a particular bioregion.

a Also carried by introduced mynas in Cook Islands, French Polynesia, the Mascarene Islands and Hawaii.

(P. domesticus), mynas were implicated by Beadell et al. (2006) as a potentially important reservoir for lineage GRW04 following its devastating introduction to Hawaii. Moreover, P. relictum lineage SGS1 and P. elongatum lineage GRW06 are carried at a high prevalence by native mynas and are known to infect introduced mynas in New Zealand (Beadell et al., 2006; Ishtiaq et al., 2006), further implicating mynas as important hosts for Plasmodium parasites across their range.

The capability of mynas to act as reservoirs could also contribute to the amplification of native Plasmodium lineages in Australia. An extension of the Novel Weapon Hypothesis is the prediction of parasite spillback, which could occur when native parasites increase their own host range and potential disease impacts by infecting successful invaders (Kelly et al., 2009; Wells et al., 2015). Introduced mynas and native Australian birds shared seven Plasmodium lineages, and the higher prevalence of Plasmodium spp. in mynas could have positive ramifications for these lineages if their infections in mynas lead to an above-normal exposure to native species (Kelly et al., 2009; Adlard et al., 2015).

While lineages GRW04, SGS1 and GRW06 are known as invasive parasite lineages that have pathogenic effects on naïve hosts, their geographic origins are uncertain (Beadell et al., 2006; Valkiünas et al., 2008; Marzal et al., 2014). Indeed, several of the lineages we recovered infecting native and introduced myna populations have been found in many avian communities across the globe (Bensch et al., 2009). While our survey suggests that introduced mynas carry some non-native lineages in Australia, tracing introduction routes using avian Plasmodium cyt- $b$ lineages is difficult (Ishtiaq et al., 2006; Lauron et al., 2014), possibly due to frequent host switching (Hellgren et al., 2014; Ricklefs et al., 2014). For instance, along with mynas, other introduced species may play a role in maintaining introduced Plasmodium parasites in New Zealand (e.g. European blackbirds and house sparrows; Ewen et al., 2012; Schoener et al., 2013), and this could be the case in Australia. Future sampling of Plasmodium parasites to include other exotic species and more rapidly evolving markers in addition to cyt- $b$ may help to resolve relationships and yield insights into the origins of lineages (Garcia-Longoria et al., 2014; Hellgren et al., 2014).

In contrast to Plasmodium, the tendency for Haemoproteus lineages to exhibit high host specificity in the southern Pacific region (Beadell et al., 2004; Clark et al., 2015; Olsson-Pons et al., 2015) presents a better opportunity to examine phylogeographic structure. For instance, lineage AUS2, recovered in introduced mynas in Australia, closely clustered with two other Haemoproteus lineages that have thus far only been recovered from native mynas. Lineage AUS2 was recovered from one myna in the 1980s and has not been recorded since, so it is probable that AUS2 was a host-specific Haemoproteus parasite that was co-introduced with mynas and was subsequently lost during expansion. Nevertheless, data on parasite morphology and experimental infections are needed to confirm host specificity (Valkiūnas et al., 2008; Dimitrov et al., 2015).

In summary, our phylogeographic analysis of a regional database indicates that introduced mynas carry a reduced diversity of haemosporidian parasites compared with native-range mynas, although overall prevalence does not differ between the two populations. Nevertheless, we suggest the high host specificity of Haemoproteus parasites in the region has allowed mynas to escape infections during secondary introductions, while host generalist Plasmodium parasites are more easily able to utilise introduced mynas as a reservoir of infection. Finally, we provide phylogeographic evidence that introduced mynas in Australia are carrying potentially invasive parasite lineages, a finding that warrants further monitoring of mynas and other introduced species that could be acting as maintenance reservoirs for harmful parasites.

\section{Acknowledgements}

We are thankful to numerous volunteers for helping with field sampling of mynas and native birds. We are especially indebted to Tweed Shire Council (Murwillumbah, NSW, Australia), Logan City Council (Brisbane, QLD, Australia), Currumbin Wildlife Hospital (Currumbin, QLD, Australia) and King Street Veterinary Hospital (Murwillumbah, NSW, Australia) for help in organising myna collections. Support was provided by BirdLife Australia and Birds Queensland (Australia) grants to N. Clark and a Griffith University (QLD, Australia) New Researcher Grant to S. M. Clegg. Fieldwork was carried out under Queensland Department of Environment and Resource Management (DERM, Australia) permit WISP10823212, New South Wales National Parks and Wildlife (NSW, Australia) Permit SL101184, Griffith University Ethics Approval ENV/01/12/AEC and a project licence from the Australian Bird and Bat Banding Authority to S. M. Clegg.

\section{Appendix A. Supplementary data}

Supplementary data associated with this article can be found, in the online version, at http://dx.doi.org/10.1016/j.ijpara.2015.08. 008. 


\section{References}

Adlard, R.D., Miller, T.L., Smit, N.J., 2015. The butterfly effect: parasite diversity, environment, and emerging disease in aquatic wildlife. Trends Parasitol. http:// dx.doi.org/10.1016/j.pt.2014.1011.1001.

Adlard, R.D., Peirce, M.A., Lederer, R., 2004. Blood parasites of birds from south-east Queensland. EMU 104, 191-196.

Asghar, M., Hasselquist, D., Hansson, B., Zehtindjiev, P., Westerdahl, H., Bensch, S., 2015. Hidden costs of infection: chronic malaria accelerates telomere degradation and senescence in wild birds. Science 347, 436-438.

Atkinson, C.T., LaPointe, D.A., 2009. Introduced avian diseases, climate change, and the future of Hawaiian Honeycreepers. J. Avian Med. Surg. 23, 53-63.

Baillie, S.M., Gudex-Cross, D., Barraclough, R.K., Blanchard, W., Brunton, D.H., 2012. Patterns in avian malaria at founder and source populations of an endemic New Zealand passerine. Parasitol. Res. 111, 2077-2089.

Baker, A.J., Moeed, A., 1987. Rapid genetic differentiation and founder effect in colonizing populations of common mynas (Acridotheres tristis). Evolution 41, $525-538$.

Balasubramaniam, S., Mulder, R.A., Sunnucks, P., Pavlova, A., Amos, J.N., Melville, J., 2013. Prevalence and diversity of avian haematozoa in three species of Australian passerine. EMU, 353-358.

Beadell, J.S., Covas, R., Gebhard, C., Ishtiaq, F., Melo, M., Schmidt, B.K., Perkins, S.L., Graves, G.R., Fleischer, R.C., 2009. Host associations and evolutionary relationships of avian blood parasites from West Africa. Int. J. Parasitol. 39, 257-266.

Beadell, J.S., Gering, E., Austin, J., Dumbacher, J.P., Peirce, M.A., Pratt, T.K., Atkinson, C.T., Fleischer, R.C., 2004. Prevalence and differential host-specificity of two avian blood parasite genera in the Australo-Papuan region. Mol. Ecol. 13, 38293844.

Beadell, J.S., Ishtiaq, F., Covas, R., Melo, M., Warren, B.H., Atkinson, C.T., Bensch, S., Graves, G.R., Jhala, Y.V., Peirce, M.A., Rahmani, A.R., Fonseca, D.M., Fleischer, R.C. 2006. Global phylogeographic limits of Hawaii's avian malaria. Proc. R. Soc. B: Biol. Sci. 273, 2935-2944.

Benjamin, Y., Hochberg, Y., 1995. Controlling the false discovery rate: a practical and powerful approach to multiple testing. J. R. Stat. Soc. B 57, 289-300.

Bensch, S., Hellgren, O., Pérez-Tris, J., 2009. MalAvi: a public database of malaria parasites and related haemosporidians in avian hosts based on mitochondrial cytochrome $b$ lineages. Mol. Ecol. Res. 9, 1353-1358.

Callaway, R.M., Ridenour, W.M., 2004. Novel weapons: invasive success and the evolution of increased competitive ability. Front. Ecol. Environ. 2, 436-443.

Chao, A., 1987. Estimating the population size for capture-recapture data with unequal catchability. Biometrics 43, 783-791.

Clark, N.J., Clegg, S.M., Lima, M.R., 2014a. A review of global diversity in avian haemosporidians (Plasmodium and Haemoproteus: Haemosporida): new insights from molecular data. Int. J. Parasitol. 44, 329-338.

Clark, N.J., Adlard, R.D., Clegg, S.M., 2014b. First evidence of avian malaria in Capricorn Silvereyes (Zosterops lateralis chlorocephalus) on Heron Island. Sunbird 44, 1-11.

Clark, N.J., Adlard, R.D., Clegg, S.M., 2015. Molecular and morphological characterization of Haemoproteus (Parahaemoproteus) ptilotis, a parasite infecting Australian honeyeaters (Meliphagidae), with remarks on prevalence and potential cryptic speciation. Parasitol. Res. http://dx.doi.org/10.1007/ s00436-00015-04380-00438.

Clark, N.J., Clegg, S.M., 2015. The influence of vagrant hosts and weather patterns on the colonization and persistence of blood parasites in an island bird. J. Biog. http://dx.doi.org/10.1111/jbi.12454.

DeWalt, S.J., Denslow, J.S., Ickes, K., 2004. Natural-enemy release facilitates habitat expansion of the invasive tropical shrub Clidemia hirta. Ecology 85, 471-483.

Dimitrov, D., Palinauskas, V., Iezhova, T.A. Bernotienè, R., Ilgūnas, M. Bukauskaitè, D., Zehtindjiev, P., Ilieva, M., Shapoval, A.P., Bolshakov, C.V., 2015. Plasmodium spp.: an experimental study on vertebrate host susceptibility to avian malaria. Exp. Parasitol. 148, 1-16.

Dove, A.D.M., Cribb, T.H., 2006. Species accumulation curves and their applications in parasite ecology. Trends Parasitol. 22, 568-574.

Drummond, A.J., Rambaut, A., 2007. BEAST: Bayesian evolutionary analysis by sampling trees. BMC Evol. Biol. 7. http://dx.doi.org/10.1186/1471-2148-11871214.

Dunn, A.M., Hatcher, M.J., 2015. Parasites and biological invasions: parallels, interactions, and control. Trends Parasitol. http://dx.doi.org/10.1016/j. pt.2014.1012.1003.

Ewen, J.G., Bensch, S., Blackburn, T.M., Bonneaud, C., Brown, R., Cassey, P., Clarke, R. H., Pérez-Tris, J., 2012. Establishment of exotic parasites: the origins and characteristics of an avian malaria community in an isolated island avifauna. Ecol. Lett. 15, 1112-1119.

Garcia-Longoria, L., Hellgren, O., Bensch, S., 2014. Molecular identification of the chitinase genes in Plasmodium relictum. Malaria J. 13, 239.

Grarock, K., Lindenmayer, D.B., Wood, J.T., Tidemann, C.R., 2013. Using invasion process theory to enhance the understanding and management of introduced species: A case study reconstructing the invasion sequence of the common myna (Acridotheres tristis). J. Environ. Manage. 129, 398-409.

Grarock, K., Tidemann, C.R., Wood, J., Lindenmayer, D.B., 2012. Is it benign or is it a pariah? Empirical evidence for the impact of the common myna (Acridotheres tristis) on Australian birds. PLoS One 7, e40622.

Grarock, K., Tidemann, C.R., Wood, J.T., Lindenmayer, D.B., 2014. Are invasive species drivers of native species decline or passengers of habitat modification?
A case study of the impact of the common myna (Acridotheres tristis) on Australian bird species. Aust. Ecol. 39, 106-114.

Griffin, A.S., Diquelou, M.C., 2015. Innovative problem solving in birds: a crossspecies comparison of two highly successful passerines. Anim. Behav. 100, 84-

Griffiths, R., Double, M.C., Orr, K., Dawson, R.J.G., 1998. A DNA test to sex most birds. Mol. Ecol. 7, 1071-1075.

Ha, H.J., Banda, M., Alley, M.R., Howe, L., Gartrell, B.D., 2013. The seroprevalence of avipoxvirus and its association with avian malaria (Plasmodium spp.) infection in introduced passerine birds in the southern regions of the North Island of New Zealand. Avian Dis. 57, 109-115.

Heger, T., Jeschke, J.M., 2014. The enemy release hypothesis as a hierarchy of hypotheses. Oikos 123, 741-750.

Hellgren, O., Atkinson, C.T., Bensch, S., Albayrak, T., Dimitrov, D., Ewen, J.G., Kim, K. S., Lima, M.R., Martin, L., Palinauskas, V., 2014. Global phylogeography of the avian malaria pathogen Plasmodium relictum based on MSP1 allelic diversity. Ecography. http://dx.doi.org/10.1111/ecog.01158.

Hellgren, O., Pérez, J., Bensch, S., 2009. A jack-of-all-trades and still a master of some: prevalence and host range in avian malaria and related blood parasites. Ecology 90, 2840-2849.

Holzapfel, C., Levin, N., Hatzofe, O., Kark, S., 2006. Colonisation of the Middle East by the invasive common Myna Acridotheres tristis L., with special reference to Israel. Sandgrouse 28, 44 .

Howe, L., Castro, I.C., Schoener, E.R., Hunter, S., Barraclough, R.K., Alley, M.R., 2012. Malaria parasites (Plasmodium spp.) infecting introduced, native and endemic New Zealand birds. Parasitol. Res. 110, 913-923.

Hu, J., De Barro, P., Zhao, H., Wang, J., Nardi, F., Liu, S.-S., 2011. An extensive field survey combined with a phylogenetic analysis reveals rapid and widespread nvasion of two alien whiteflies in China. PLoS One 6, e16061.

Ishtiaq, F., Beadell, J.S., Baker, A.J., Rahmani, A.R., Jhala, Y.V., Fleischer, R.C., 2006. Prevalence and evolutionary relationships of haematozoan parasites in native versus introduced populations of common myna Acridotheres tristis. Proc. R. Soc B: Biol. Sci. 273, 587-594.

Ishtiaq, F., Gering, E., Rappole, J.H., Rahmani, A.R., Jhala, Y.V., Dove, C.J., Milensky, C., Olson, S.L., Peirce, M.A., Fleischer, R.C., 2007. Prevalence and diversity of avian hematozoan parasites in Asia: a regional survey. J. Wildl. Dis. 43, 382-398.

Ivanova, K., Zehtindjiev, P., Mariaux, J., Georgiev, B.B., 2015. Genetic diversity of avian haemosporidians in Malaysia: cytochrome $b$ lineages of the genera Plasmodium and Haemoproteus (Haemosporida) from Selangor. Infect. Gen. Evol. 31, 33-39.

Keane, R.M., Crawley, M.J., 2002. Exotic plant invasions and the enemy release hypothesis. Trends Ecol. Evol. 17, 164-170.

Kelly, D.W., Paterson, R.A., Townsend, C.R., Poulin, R., Tompkins, D.M., 2009. Parasite spillback: a neglected concept in invasion ecology? Ecology 90, 2047-2056.

Lake, J.C., Leishman, M.R., 2004. Invasion success of exotic plants in natura ecosystems: the role of disturbance, plant attributes and freedom from herbivores. Biol. Conserv. 117, 215-226.

Lauron, E.J., Loiseau, C., Bowie, R.C.K., Spicer, G.S., Smith, T.B., Melo, M., Sehgal, R.N. M., 2014. Coevolutionary patterns and diversification of avian malaria parasites in African sunbirds (Family Nectariniidae). Parasitology. http://dx.doi.org $10.1017 /$ S0031182014001681.

Lee, C.E., 2002. Evolutionary genetics of invasive species. Trends Ecol. Evol. 17, 386391.

Loiseau, C., Harrigan, R.J., Cornel, A.J., Guers, S.L., Dodge, M., Marzec, T., Carlson, J.S. Seppi, B., Sehgal, R.N.., 2012. First evidence and predictions of Plasmodium transmission in Alaskan bird populations. PLoS One 7, e44729.

Martin, W., 1996. The current and potential distribution of the common myna Acridotheres tristis in Australia. EMU 96, 166-173.

Marzal, A., Garcia-Longoria, L., Callirgos, J.M., Sehgal, R.N., 2014. Invasive avian malaria as an emerging parasitic disease in native birds of Peru. Biol. Invasions. http://dx.doi.org/10.1007/s10530-10014-10718-x.

Marzal, A., Ricklefs, R.E., Valkiūnas, G., Albayrak, T., Arriero, E., Bonneaud, C., Czirjak, G.A., Ewen, J., Hellgren, O., Horakova, D., Iezhova, T.A., Jensen, H. Krizanauskiene, A., Lima, M.R., de Lope, F., Magnussen, E., Martin, L.B., Møller A.P., Palinauskas, V., Pap, P.L., Pérez, J., Sehgal, R.N.M., Soler, M., Eszter, S. Westerdahl, H., Zetindjiev, P., Bensch, S., 2011. Diversity, loss, and gain of malaria parasites in a globally invasive bird. PLoS One 6, e21905.

Medeiros, M.C., Hamer, G.L., Ricklefs, R.E., 2013. Host compatibility rather than vector-host-encounter rate determines the host range of avian Plasmodium parasites. Proc. R. Soc. B: Biol. Sci. http://dx.doi.org/10.1098/rspb.2012.2947.

Olsson-Pons, S., Clark, N.J., Ishtiaq, F., Clegg, S.M., 2015. Differences in host species relationships and biogeographic influences produce contrasting patterns of prevalence, community composition and genetic structure in two genera of avian malaria parasites in southern Melanesia. J. Anim. Ecol. http://dx.doi.org/ $10.1111 / 1365-2656.12354$.

Palinauskas, V., Valkiūnas, G., Križanauskienė, A., Bensch, S., Bolshakov, C.V., 2009 Plasmodium relictum (lineage P-SGS1): Further observation of effects on experimentally infected passeriform birds, with remarks on treatment with Malarone (TM). Exp. Parasitol. 123, 134-139.

Peacock, D.S., Van Rensburg, B.J., Robertson, M.P., 2007. The distribution and spread of the invasive alien common myna, Acridotheres tristis L. (Aves: Sturnidae), in southern Africa. S. Afr. J. Sci. 103, 465-473.

Pell, A., Tidemann, C., 1997. The ecology of the common myna in urban nature reserves in the Australian Capital Territory. EMU 97, 141-149.

Posada, D., Crandall, K.A., 1998. MODELTEST: testing the model of DNA substitution Bioinformatics $14,817-818$. 
Richardson, D., Jury, F., Blaakmeer, K., Komdeur, J., Burke, T., 2001. Parentage assignment and extra-group paternity in a cooperative breeder: The Seychelles warbler (Acrocephalus sechellensis). Mol. Ecol. 10, 2263-2273.

Ricklefs, R.E., Outlaw, D.C., Svensson-Coelho, M., Medeiros, M.C.I., Ellis, V.A., Latta, S. 2014. Species formation by host shifting in avian malaria parasites. Proc. Natl. Acad. Sci. U.S.A. 111, 14816-14821.

Santiago-Alarcon, D., Palinauskas, V., Schaefer, H.M., 2012. Diptera vectors of avian Haemosporidian parasites: untangling parasite life cycles and their taxonomy. Biol. Rev. 87, 928-964.

Schoener, E.R., Banda, M., Howe, L., Castro, I.C., Alley, M.R., 2013. Avian malaria in New Zealand. N. Z. Vet. J. 62, 189-198.

Schuler, K. Green, D., Justice-Allen, A, Jaffe, R. Cunningham, M., Thomas, N Spalding, M., Ip, H., 2012. Expansion of an exotic species and concomitant disease outbreaks: pigeon paramyxovirus in free-ranging Eurasian collared doves. EcoHealth 9, 163-170.

Scordato, E.S., Kardish, M.R., 2014. Prevalence and beta diversity in avian malaria communities: host species is a better predictor than geography. J. Anim. Ecol. 83, 1387-1397.

Sol, D., Griffin, A.S., Bartomeus, I., Boyce, H., 2011. Exploring or avoiding novel food resources? The novelty conflict in an invasive bird. PLoS One 6, e19535.

Tompkins, D.M., White, A.R., Boots, M., 2003. Ecological replacement of native red squirrels by invasive greys driven by disease. Ecol. Lett. 6, 189-196.

Valkiūnas, G., 2005. Avian Malaria Parasites and Other Haemosporida. CRC Press, Boca Raton, FL, USA.

Valkiūnas, G., Bensch, S., Iezhova, T.A., Krizanauskiene, A., Hellgren, O., Bolshakov, C. V., 2006. Nested cytochrome $b$ polymerase chain reaction diagnostics underestimate mixed infections of avian blood haemosporidian parasites: microscopy is still essential. J. Parasitol. 92, 418-422.
Valkiūnas, G., Iezhova, T.A., Loiseau, C., Sehgal, R.N.M., 2009. Nested cytochrome $b$ polymerase chain reaction diagnostics detect sporozoites of hemosporidian parasites in peripheral blood of naturally infected birds. J. Parasitol. 95, 15121515.

Valkiūnas, G., Palinauskas, V., Ilgunas, M., Bukauskaite, D., Dimitrov, D., Bernotiene, R., Zehtindjiev, P., Ilieva, M., Iezhova, T., 2014. Molecular characterization of five widespread avian haemosporidian parasites (Haemosporida), with perspectives on the PCR-based detection of haemosporidians in wildlife. Parasitol. Res., 1-13

Valkiūnas, G., Zehtindjiev, P. Dimitrov, D., Krizanauskiene, A. Iezhova, T.A., Bensch, S., 2008. Polymerase chain reaction-based identification of Plasmodium (Huffia) elongatum, with remarks on species identity of haemosporidian lineages deposited in GenBank. Parasitol. Res. 102, 1185-1193.

van Riper III, C., van Riper, S.G., Goff, M.L., Laird, M., 1986. The epizootiology and ecological significance of malaria in Hawaiian land birds. Ecol. Monogr. 56, 327344.

Vavrek, M.J., 2011. Fossil: palaeoecological and palaeogeographical analysis tools. Palaeontol. Electron. 14, 16

Waldenström, J., Bensch, S., Hasselquist, D., Östman, Ö., 2004. A new nested polymerase chain reaction method very efficient in detecting Plasmodium and Haemoproteus infections from avian blood. J. Parasitol. 90, 191-194.

Wells, K., O'Hara, R.B., Morand, S., Lessard, J.-P., Ribas, A., 2015. The importance of parasite geography and spillover effects for global patterns of host-parasite associations in two invasive species. Divers. Distrib. 21, 477-486.

Zamora-Vilchis, I., Williams, S.E., Johnson, C.N., 2012. Environmental temperature affects prevalence of blood parasites of birds on an elevation gradient: implications for disease in a warming climate. PLoS One 7, e39208. 